\title{
Flow resistance in a compound gravel-bed bend
}

\author{
HOSSEIN AFZALIMEHR, MANOUCHEHR HEIDARPOUR and \\ ALIREZA SALIMI
}

Department of Water Engineering, Isfahan University of Technology, Isfahan, Iran e-mail: hafzali@cc.iut.ac.ir

MS received 24 January 2006; revised 4 October 2006

\begin{abstract}
In this paper, the effect of a gravel-bed in a compound bend (similar to sinusoidal top view) of a natural river (Zayandehrud River flowing through Isfahan, Iran) has been investigated for flow resistance analysis, measuring the velocity with a micro current meter. The data were analysed and the following observations were made.

In a compound bend, the law of the wall can be valid for up to $66 \%$ of the flow depth from the bed. The parabolic law is the most effective method for the determination of shear velocity. Based on the existing criteria for verifying the equilibrium boundary layer, the flow cannot be in equilibrium. The shear stress distribution and the sediment transport parameters have considerable influence on resistance to flow. Froude number and the flow depth relative to the representative gravel size have little effect on the flow resistance estimation.
\end{abstract}

Keywords. Compound bend; gravel-bed; sediment transport; shear-stress distribution; flow resistance; fluvial hydraulics.

\section{Introduction}

Rivers seldom flow straight over a small distance and follow often meandering paths. Flow characteristics through a bend are helicoidal, and a complete description of the velocity distribution requires accurate estimation of shear velocity. In addition, knowledge of the flow characteristics in a compound bend is essential for analyzing the river meandering and river training problems.

Fluid mixing between the center and sides of a bed is greater than that in a straight channel. The primary reason for this difference is that the shear stress distribution is induced by the centrifugal force having a lateral momentum transfer. This force disappears after leaving a bend exit. Thus, the turbulent shear stress is the resistance that the flow has to overcome in transforming from a primary flow into a secondary flow pattern and vice versa.

The increase in flow resistance in a meandering path can be attributed to the following reasons.

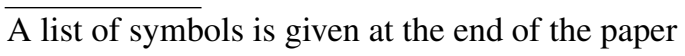


(1) Internal fluid resistance due to secondary flow: Presence of the secondary flow modifies the primary flow pattern considerably since the high velocity streamlines move closer to the outer bank, and velocity variation in the radial direction is considerably different from that in main flow.

(2) Boundary resistance due to transverse shear: Transverse shear stress leads the redistribution of the velocities along the vertical and across the width due to secondary currents.

In this study, for quantifying flow resistance, the Darcy-Wiesbach coefficient $(f)$ is applied as follows.

$$
(8 / f)^{1 / 2}=u_{m} / u_{*}
$$

in which $u_{m}$ is the mean velocity for each velocity profile and $u_{*}$ is the shear velocity. In fact, the difference in flow resistance estimation between a bend reach and a straight one should be related to $u_{m}$ and $u_{*}$ values. Bagnold (1960), Leopold et al (1960), Rozovskii (1957), Morisawa (1968), Chang (1984), Odgaard (1986), Fores \& Spence (1995) and Fukuoka et al (2001) among many others have studied different aspects of flow resistance in meandering rivers.

The main objective of this study is to apply the boundary-layer theory in order to investigate flow resistance along a compound bend in a gravel-bed river. Also the following aspects are considered in this paper.

(1) Investigation of the fully developed flow in tangential and radial directions of a compound bend, and likewise, verification of flow equilibrium along the bend.

(2) Investigation and comparison of the shear velocity estimation using logarithmic law and parabolic law within a compound bend.

(3) Considering the influence of the shear stress distribution parameter, the sediment mobility parameter, the Froude number and the relative depth, on the flow resistance in a compound bend.

\section{Site selection}

The site selected was a compound bend of the Zayenderud river, which is a gravel-bed river in the Isfahan Province of central Iran. Figure 1 shows the plan of the selected compound bend. The grain-size characteristic of the bend portion was $d_{84}=39.8 \mathrm{~mm}$ of median grain size $d_{50}=22.3 \mathrm{~mm}$. The flow discharge varied from $11.81 \mathrm{~m}^{3} / \mathrm{s}$ to $16.45 \mathrm{~m}^{3} / \mathrm{s}$ during the field measurements in Summer, 2001. The river width varied from $32 \mathrm{~m}$ to $47 \mathrm{~m}$ along the compound bend and the flow depth varied from $0.20 \mathrm{~m}$ to $0.90 \mathrm{~m}$. The range of the Froude and Reynolds numbers were $0.189 \leq \mathrm{Fr} \leq 0.0567$ and $3.2 \times 10^{5} \leq \mathrm{Re} \leq 4.44 \times 10^{5}$, respectively. Also the bed slope of the bend was relatively flat.

The flow measurements were taken at eight consecutive cross-sections of five velocity profiles in each cross-section. The velocity profiles were measured at the central axis and two other vertical lines on either side of the central axis. Figure 2 shows a typical cross-section of a compound bend.

At each cross-section, vertical velocity profiles were measured at $2 \mathrm{~m}$ intervals across the bend. A micro current-meter was used for the velocity measurements. The velocities were measured starting from the near bed and then approximately at $1 \mathrm{~cm}$ intervals for $y / h<0 \cdot 2$ and $2 \mathrm{~cm}$ or $3 \mathrm{~cm}$ for $0 \cdot 2<y / h<1$. At each point of the velocity profile, measurements 


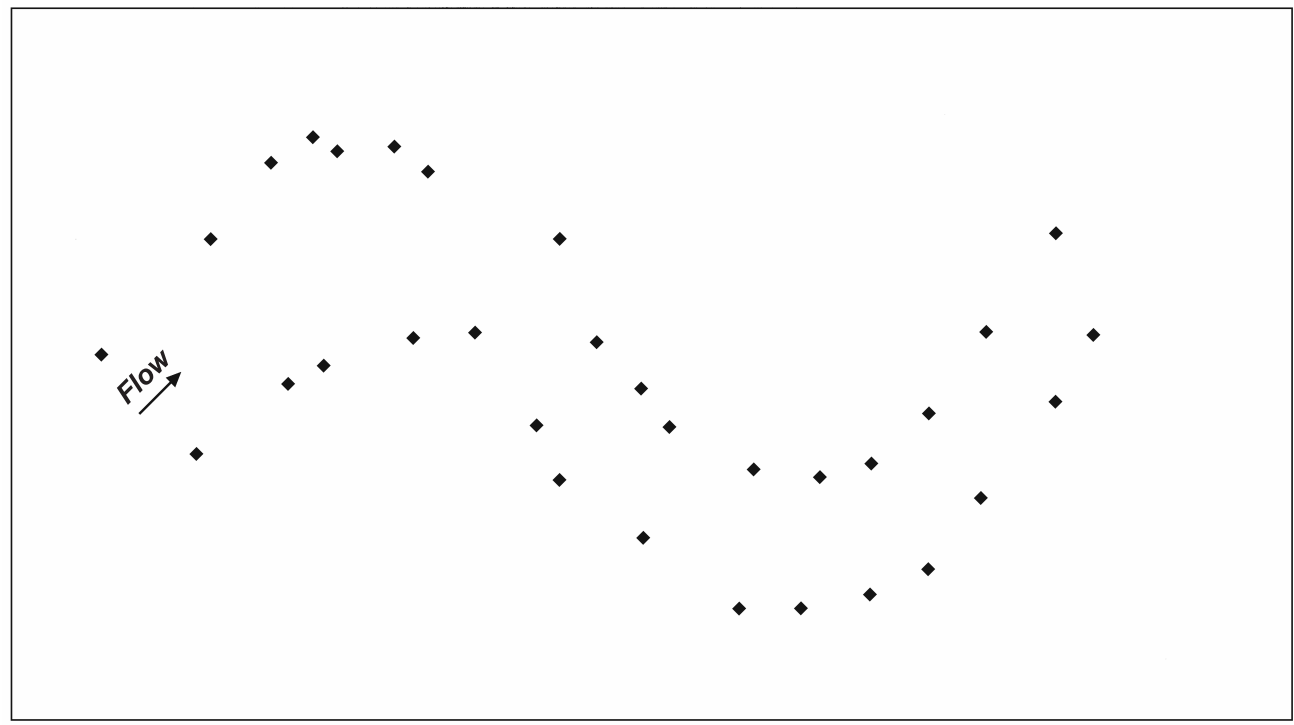

Figure 1. Plan of the compound bend.

were taken four times and the average values were taken as the point velocity in the profiles. All measurements were carried out during relatively stable flow conditions.

In order to obtain a good estimate of the shear velocities from the velocity distributions, it is necessary to present the reference surface for flow depth determination. Accordingly, $0 \cdot 25 d_{84}$ under the top of grains was selected as the reference surface. Since the thalweg of the river was not superposed on the central axis, the estimation of bottom slope was not considered in this study, due to difficulty of field measurements.

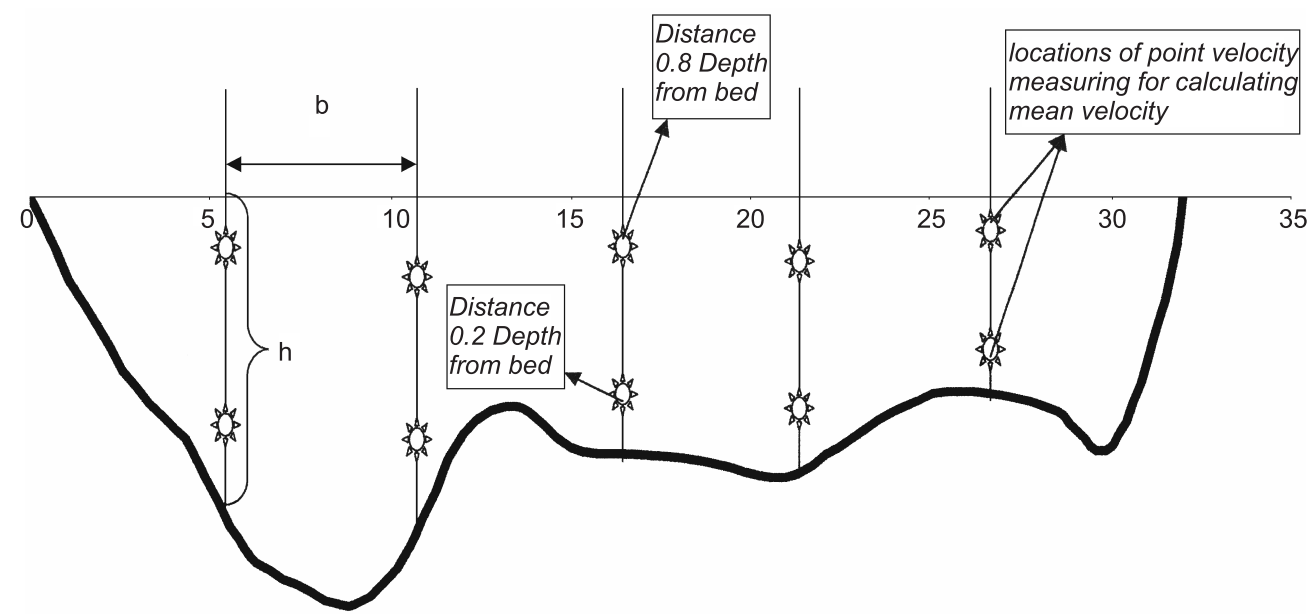

Figure 2. Typical cross section of the compound bend. 


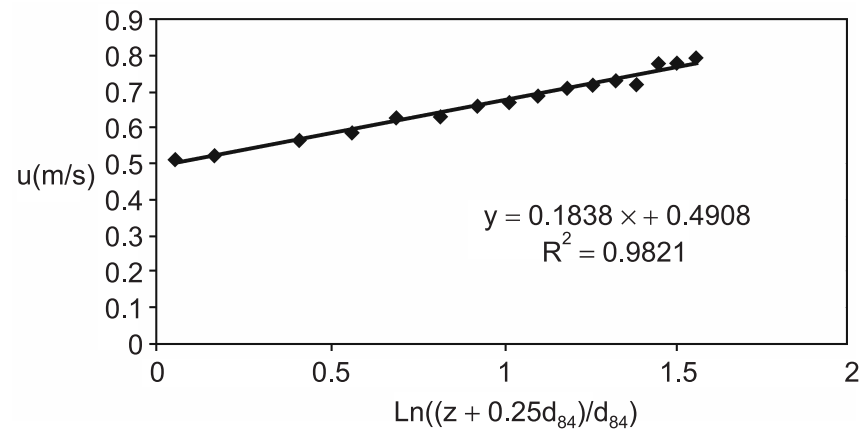

Figure 3. Validation of the law of the wall.

It should also be mentioned that river bends are generally irregular, so their characteristics cannot be defined easily. Accordingly, it was assumed that the selected compound bend, in this study, is composed of two simple circles, where the bend of each circle may be estimated as follows:

$$
\begin{aligned}
& L_{1}=R_{1} \beta_{1}, \\
& L_{2}=R_{2} \beta_{2},
\end{aligned}
$$

in which $\beta_{1}, \beta_{2}$ are the circle bend angles (in radians), and $R$ and $L$ are the radius and the length of bend respectively (in metres).

According to the boundary layer theory, the velocity distribution may be divided into two regions: (1) Inner region, which is the region near the bed and (2) outer region, which is far from the bed and is up to the free surface. The measured data in this study indicate that the inner region follows a log-law (figure 3), while the outer region follows a parabolic law (figure 4). The relative depth $(y / h)$ at the point that separates the inner region from the outer region, varies from 9 to $66 \%$. Figure 5 shows a comparison of estimated shear velocity using the log-law and the parabolic law at the central axis of the selected bend. According to this figure, the two methods are reasonably compatible, although the parabolic law is less sensitive to the reference surface adjustment. Thus, in this study, the shear velocity was evaluated by the parabolic law and was applied for flow resistance estimation.

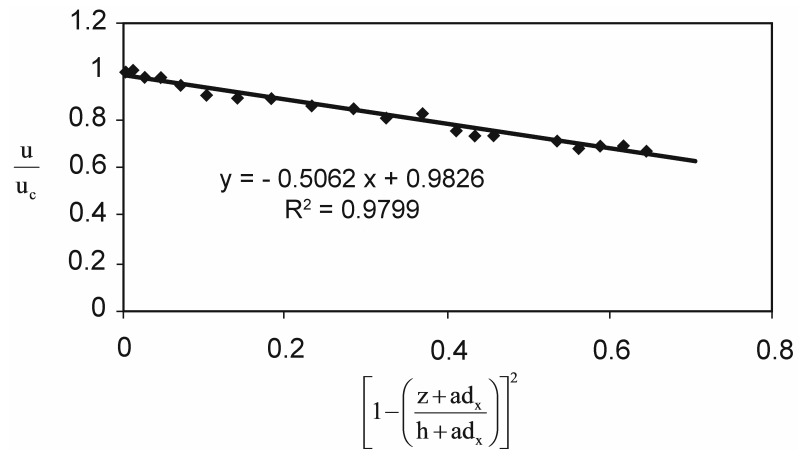

Figure 4. Validation of the parabolic law. 


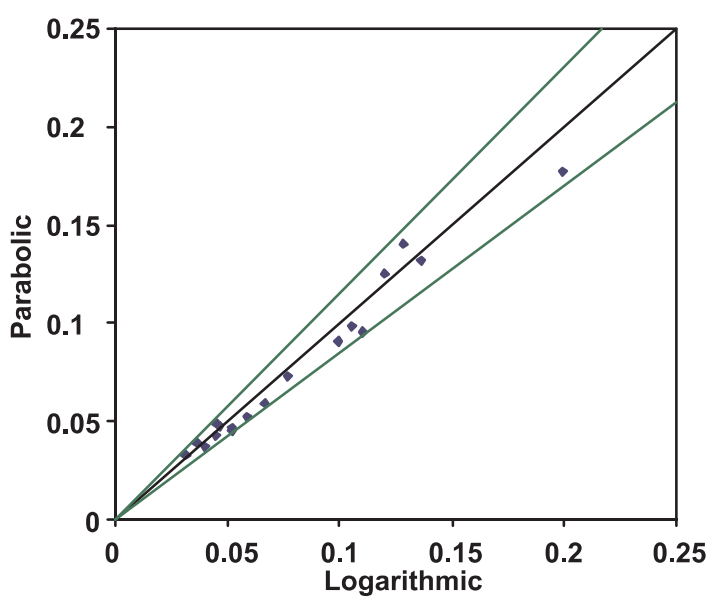

Figure 5. Comparison of estimated shear velocity using the log-law and the parabolic law.

\section{Results}

\subsection{Verification of equilibrium flow}

Equilibrium flow does not depend on its upstream condition, and its representation is invariant along the flow direction (Graf \& Altinakar 1998). According to them, for equilibrium flow, the pressure gradient parameter is defined as follows,

$$
\beta=\left(\delta_{*} / \tau\right)(-S+\mathrm{d} h / \mathrm{d} x),
$$

where $\delta_{*}$ is the boundary layer displacement thickness, $\tau$ is the bed shear stress, $S$ is the bed slope and $\mathrm{d} h / \mathrm{d} x$ is the water surface variation. The pressure gradient $\beta$ should remain constant for equilibrium flow.

Clauser (1956) stated that the equilibrium flow can also be investigated by using the shape parameter $H$ defined as,

$$
H=\delta_{*} / \theta,
$$

where $\theta$ is the boundary layer momentum thickness. The boundary layer displacement thickness $\delta_{*}$ is given by

$$
\delta_{*}=\int_{0}^{h}\left(1-\left(u / u_{\max }\right)\right) \mathrm{d} y,
$$

and the boundary layer momentum thickness $\theta$ is given by

$$
\theta=\int_{0}^{h}\left(u / u_{\max }\right)\left(1-\left(u / u_{\max }\right)\right) \mathrm{d} y .
$$

Accordingly, $H$ remains nearly constant for equilibrium flows in flow direction. Figure 6 and 7 show the longitudinal evolution of $\beta$ and $H$, respectively. It can be considered that the $H$-values are not practically constant along the flow direction in a compound bend. Kironoto $\&$ Graf (1995) showed that in a straight flume with a gravel bed, $H=1 \cdot 55$. Figure 5 indicates that in a compound bend $H$ varies from 1.6 to 2 . 


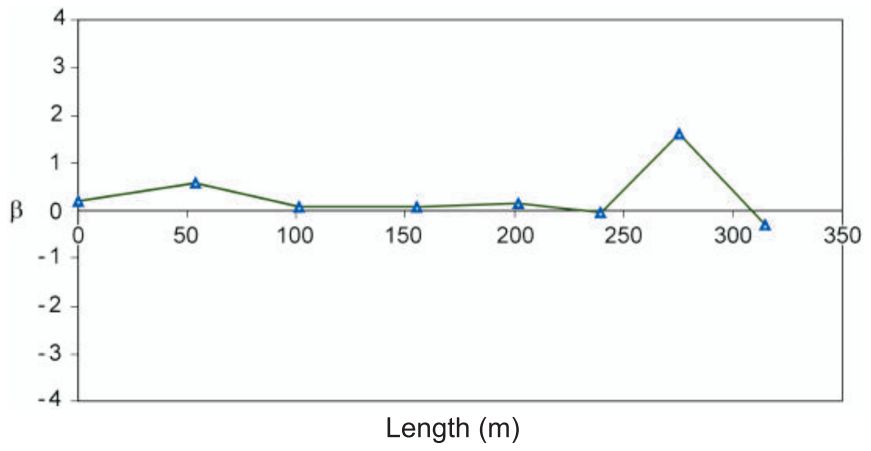

Figure 6. Longitudinal evolution of the pressure gradient parameter $(\beta)$.

\subsection{Presentation of profiles and fully developed flow in tangential and radial directions}

Using the velocity profile measurements in the tangential and the redial directions, the fully developed flow is investigated along a compound bend. Figure 8 shows the velocity profiles along a compound bend. Accordingly, there is a steep velocity gradient near the bed with increased point velocities in the vertical direction. The maximum velocity occurs at the free surface for all measured velocity profiles. Based on figure 8 , the velocity profiles have similar distribution. The scatter is considered in the profiles which corresponds to the hard conditions of velocity measurement near the bed, especially for $y / h<0.1$ as well as the complexity of flow in a river and the unknown factors affecting the velocity distribution. It is evident that under controlled conditions in the laboratory, velocity profiles are completely similar. According to figure 8, we can consider that the flow is fully developed in the tangential direction, so that the shear velocity and the resulting flow resistance can be determined using each velocity profile.

\subsection{Influence of sediment transport parameter on flow resistance}

The sediment transport parameter is defined as the ratio of the Shield parameter to the critical value of this parameter $\tau_{*} / \tau_{* c}$, where $\tau_{*}=$ Shield parameter, $\tau /\left[\left(\gamma_{s}-\gamma\right) d_{84}\right], \tau=$ bed shear stress, $\gamma_{s}=$ specific weight of sediment, $\gamma=$ specific weight of water and $d_{84}=$ representative bed sediment size, $84 \%$ by weight of the sediment being finer than this. Figure 9

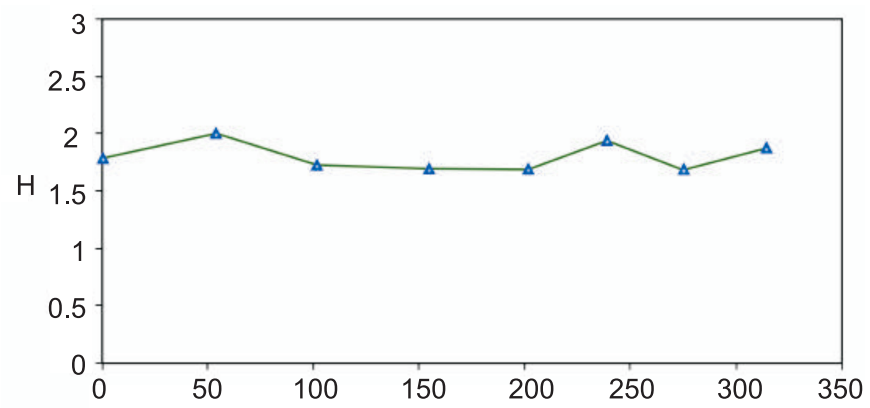

Figure 7. Longitudinal evolution of shape parameter $(H)$. 


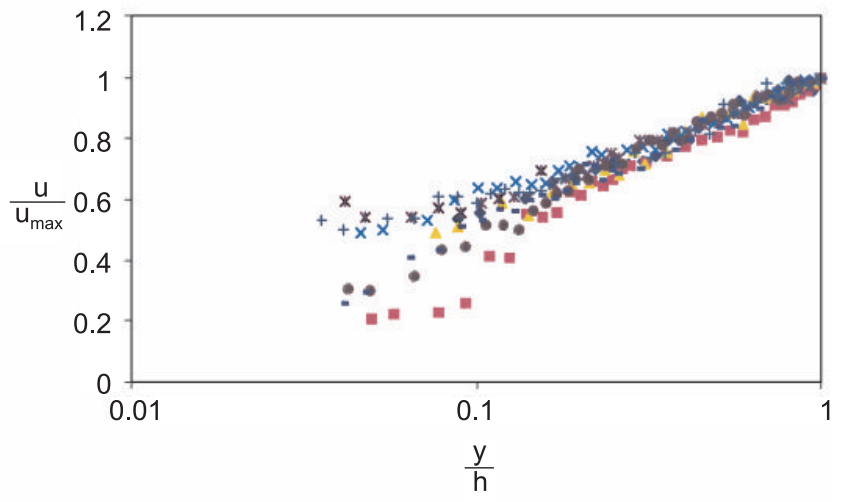

Figure 8. Presentation of fully developed flow in tangential direction.

shows that there is an inverse relationship between flow resistance and $\tau_{*} / \tau_{* c}$ value. Also the coefficient of determination $R^{2}=0.512$ indicates that in spite of considerable scatter in figure 9 , the sediment transport parameter has remarkable effect on the estimation of flow resistance. The reasons for such a scatter can be attribute to 3D flow in a river, and the difficulty of measuring flow depth and velocity in shallow water in mountain rivers.

\subsection{Influence of the shear stress distribution parameter on flow resistance}

According to Bathurst (1985), the application of uniform flow resistance in the presence of a nonuniform bed profile causes overestimation of flow resistance. This can be true for nonuniformity of the flow depth also, due to the nonuniform cross-section as well as variation in bend path. Also, such a variation impose a nonuniform shear stress distribution, which plays a direct role in the estimation of flow resistance. In fact, the considerable difference between the uniform and the nonuniform flow resistance for a constant discharge, flow depth and slope is due to the difference in shear stress distribution between two flows. On the other

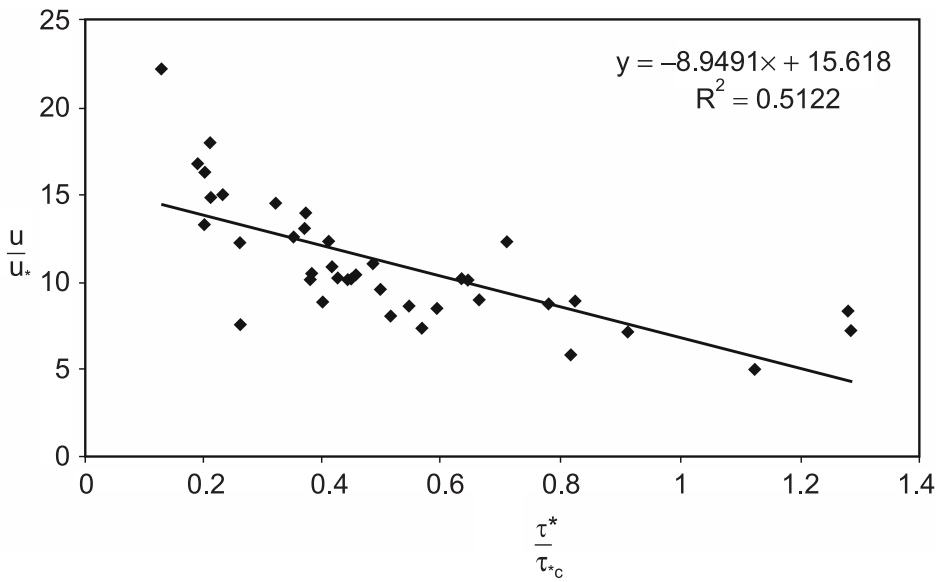

Figure 9. Relationship between the sediment transport parameter and flow resistance. 


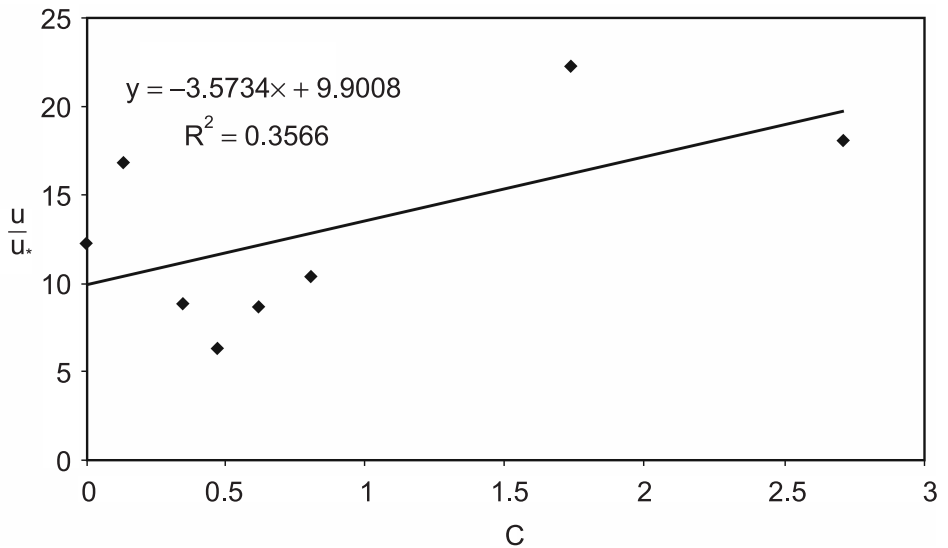

Figure 10. Relationship between the shear stress distribution parameter and flow resistance.

hand, the bed shear stress effect cannot be described by bulk parameters such as $\left(g h S_{f}\right)^{0.5}$, where $g=$ gravitational acceleration, $h=$ flow depth and $S_{f}=$ energy slope. According to Bathurst (1982), the shear stress distribution parameter is defined as follow:

$$
C=\left(\bar{u}_{m} / \bar{u}_{*}\right)-\overline{\left[u_{m} / u_{*}\right]}
$$

where $\bar{u}_{m}$ is the mean flow velocity at a cross-section, $\bar{u}_{*}$ is the mean shear velocity at a crosssection, $u_{m}$ is the mean depth integrated flow velocity at each profile of velocity, and $u_{*}$ is the local shear velocity obtained from a velocity profile. For uniform flow $C$ will be equal to zero.

According to figure 10, in the range of $C$, as $0.5<C<2$ with augmentation of $C$, the flow resistance increases. On the other hand, with unspecific behaviour of $C$ in the range of $0<C<0.5$, no conclusion can be obtained. It seems that more data are required for arriving at a conclusive result.

\subsection{Influence of relative depth $h / d_{84}$ on $u / u_{*}$}

The huge scatter in figure 11 and weak coefficient of determination $R^{2}=0 \cdot 14$ indicate that the relative depth has less influence on a bent path than on a straight path. Also figure 11 shows that for $\log \left(h / d_{84}\right)=0.95$, the value of $u / u_{*}$ varies from 7 to 11 , which is almost $40 \%$ difference. This variation for larger values of $\log h / d_{84}$ is more considerable. For example, for a constant value of $\log \left(h / d_{84}\right)$, the value of $u / u_{*}$ changes from 8 to 22.5 , which is $280 \%$ difference. Accordingly, the relative depth cannot be considered as an input variable of flow resistance in a compound bend. This result is, on the contrary, of uniform flow resistance formulation (Afzalimehr \& Anctil 1998).

\subsection{Influence of Froude number on $u / u_{*}$}

According to figure 12, it seems that the Froude number $(F r)$ has no influence on the estimation of flow resistance in a compound bend. However, Jarrett $(1984,1991)$, and Afzalimehr \& Anctil (1998) showed that the Froude number has significant effect on the flow resistance prediction for uniform flow in a straight channel. This may be explained by the strong 


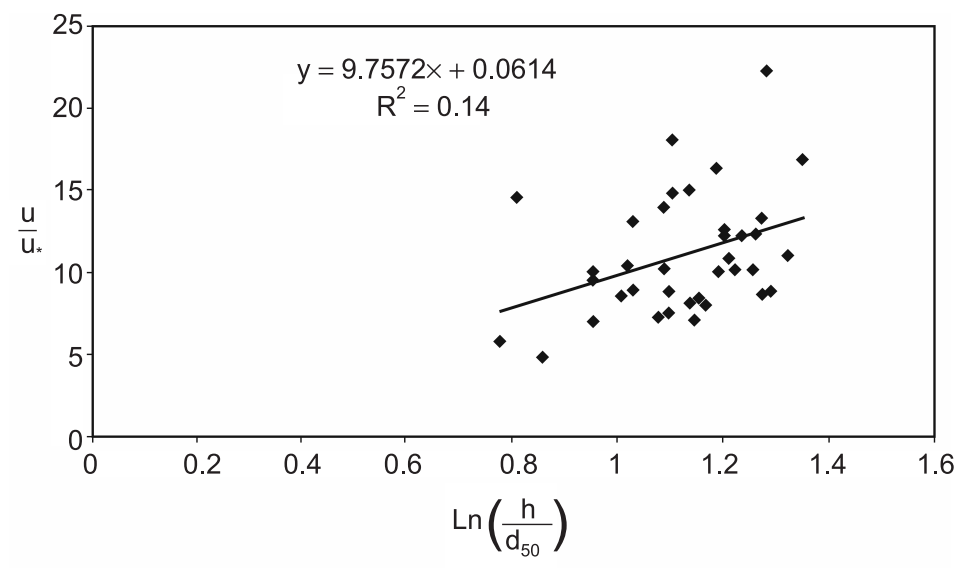

Figure 11. Relationship between the logarithm of relative depth and flow resistance.

effect of $C$ and $\tau_{*} / \tau_{* c}$ in nonuniform flow due to secondary flow effects in a compound bend.

\section{Conclusions}

(1) According to this study, the flow is fully developed in tangential and radial directions of a compound bend. Thus, the Darcy-Weisbach coefficient can be applied to quantify flow resistance in a compound bend.

(2) Based on criteria by several investigators flow in a compound bend is not in equilibrium.

(3) In a compound bend, the parameters of sediment transport and shear stress distribution are the most effective for prediction of flow resistance.

(4) Froude number and the relative depth $\left(h / d_{84}\right)$ have little influence on flow-resistance prediction in a compound bend.

(5) More field data are required for nonuniform flow analysis in a compound bend to obtain better understanding of parameters affecting flow resistance.

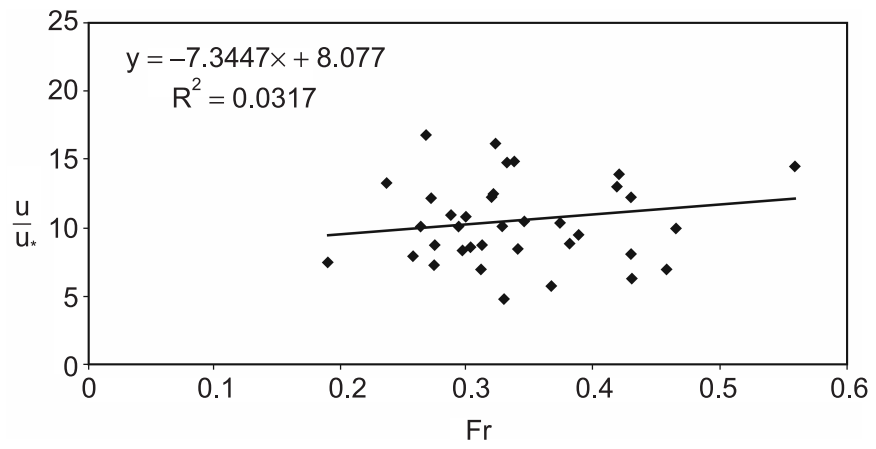

Figure 12. Relationship between the Froude number and flow resistance. 


\section{List of symbols}

$C \quad$ the shear stress distribution parameter;

$\mathrm{d} h / \mathrm{d} x$ the water surface variation;

$d_{84} \quad 84 \%$ finer particle diameter;

Fr Froude number;

$g \quad$ gravitational acceleration;

$h \quad$ flow depth;

$L \quad$ the length of bend;

$R \quad$ the radius of bend;

Re Reynolds number;

$S \quad$ the bed slope;

$S_{f} \quad$ energy slope;

$u_{m} \quad$ the mean velocity for each velocity profile;

$\bar{u}_{m} \quad$ the mean flow velocity at a cross-section;

$u_{*} \quad$ the local shear velocity;

$\bar{u}_{*} \quad$ the mean shear velocity at a cross-section;

$y \quad$ distance from the bed;

$\beta \quad$ the pressure gradient parameter

$\beta_{1}, \beta_{2}$ the circle bend angles;

$\gamma \quad$ water specific weight;

$\gamma_{s} \quad$ sediment specific weight;

$\delta_{*} \quad$ the boundary layer displacement thickness;

$\theta \quad$ the boundary layer momentum thickness;

$\tau \quad$ the bed shear stress;

$\tau_{*} \quad$ Shield parameter.

\section{References}

Afzalimehr H, Anctil F 1998 Estimation of gravel-bed river flow resistance. J. Hydraul. Eng., Am. Soc. Civil Eng. 124: 1054-1058

Bagnold R A 1960 Some aspects of the shape of river meanders. Professional paper 282-E, US Geological Survey, Washington, DC, 135-144

Bathurst J C 1982 Theoretical aspects of flow resistance. Gravel-bed rivers (eds) R D Hey, J C Bathurst, C R Thorne (New York: Wiley) p. 83

Bathurst J C 1985 Flow resistance estimation in mountain rivers. J. Hydraul. Eng., Am. Soc. Civil Eng. 111: 625-643

Chang H H 1984 Variation of flow resistance through curved channels. J. Hydraul. Eng., Am. Soc. Civil Eng. 110: 1722-1734

Clauser F H 1956 The turbulent boundary layers. Adv. Appl. Mech. 4: 1-15

Fares Y R, Spence G J 1995 Spatial variations of flow resistance in meandering channels. Proc. Int. Conf. Hydroscience Engineering, Beijing, China, pp 230-238

Fukuoka S, Watanabe A, Takatsugu W 2001 Study on the accuracy of discharge management in compound meandering channel by 3-D numerical analysis. Annu. J. Hydraul. Eng. Jpn. Soc. Civil Eng. 45: 577-582

Graf W H, Altinakar M S 1998 Fluvial hydraulics flow and transport processes in channels of simple geometry (New York: Wiley)

Jarrett R D 1984 Hydraulics of high-gradient streams. J. Hydraul. Eng., Am. Soc. Civil Eng. 110: $1519-1539$ 
Jarrett R D 1991 Hydraulics of mountain rivers. Channel flow resistance. Centennial of Manning's formula (ed.) B C Yen (Highlands Ranch, CO: Water Resources Publications) p. 287

Kironoto B A, Graf W H 1995 Turbulence characteristics in rough non-uniform open channel flow. Water Maritime Eng., Proc. Inst. Civ. Eng. (London) 112: 336-348

Leopold L B, Bagnold R A, Wolman M G, Brush L M 1960 Flow resistance in sinuous or irregular channels. Professional paper 282-D, US Geological Survey, Washington, DC, 111-134

Morisawa M 1968 Streams: Their dynamics and morphology (New York: McGraw-Hill)

Odgaard A J 1986 Meander-flow model I: Development. J. Hydraul. Eng., Am. Soc. Civil Eng. 112: $1117-1136$

Rozovskii I L 1957 Flow of water in bends of open channels (Kiev: Ukrainian SSR Acad. Sci.); translated from the Russian by the Israel Program for Scientific Translation Jerusalem Israel 1961 (available from Office of Technical Services, US Department of Commerce, Washington, DC, PST Catalogue 363 OTS 60-51133) 